Terr. Atmos. Ocean. Sci., Vol. 18, No. 5, 901-921, December 2007

\title{
Local Effects on Strain Seismograms at Matsushiro Seismological Observatory - 2. Rayleigh Waves
}

\author{
Taishi Okamoto ${ }^{1,}{ }^{*}$, Yutaka Ikegami ${ }^{1}$, and Kazuya Kokubo ${ }^{2,3}$
}

(Manuscript received 18 July 2006, in final form 8 May 2007)

\begin{abstract}
We evaluate local effects on strain seismograms for a Rayleigh wave observed at Matsushiro Seismological Observatory, Japan Meteorological Agency, central Japan, by applying a method proposed in a previous report (Okamoto et al. 2007). The method involves examination of polarization angles, local phase velocity, and accuracy of velocity seismograms. The results are as follows: 1) Polarization angles of observed strain seismograms agree with expected ones from those of velocity seismograms also observed at Matsushiro; 2) Local phase velocity estimated by comparison between strain and velocity seismograms is $\mathbf{5 4 \%}$ larger than the theoretical value calculated from the PREM velocity model; 3) Velocity spectra observed at Matsushiro have almost the same amplitude as an average of those at F-net observation stations near Matsushiro. These results indicate that both EW and NS component strain seismograms observed at Matsushiro have been reduced by $35 \%$ in amplitude for a Rayleigh wave due to local heterogeneity. The local effects on a Rayleigh wave are quite different from that on a Love wave obtained in the previous report.
\end{abstract}

(Key words: Strain seismogram, Rayleigh wave, Phase velocity)

\section{INTRODUCTION}

An extensometer (or a strainmeter) has an advantage over a seismometer by having good frequency response up to the DC component, and can be used as a very broadband seismometer.

\footnotetext{
${ }^{1}$ Department of Geophysics, Graduate School of Science, Kyoto University, Kyoto, Japan

2 Matsushiro Seismological Observatory, Japan Meteorological Agency, Nagano, Japan

${ }^{3}$ Seismological and Volcanological Department, Japan Meteorological Agency,Tokyo, Japan

* Corresponding author address: Prof. Taishi Okamoto, Department of Geophysics, Graduate School of Science, Kyoto University, Kyoto, Japan; E-mail: dollar@kugi.kyoto-u.ac.jp doi: 10.3319/TAO.2007.18.5.901(T)
} 
In addition to that, strainmeters have been installed and are in operation in a very deep tunnel (Takemoto et al. 2004) and borehole (Ishii et al. 2003); this type of set up provides ideal conditions for the detection of tiny signals essential for the research of deep Earth structure.

Recently, some researchers have taken advantage of this and utilized strain seismograms in seismological applications, especially in the longer period range. For example, Kawasaki et al. (1991) applied strain seismograms to detect silent earthquakes. Miyabayashi et al. (1999) and Komaki et al. (2006) also applied strain seismograms to detect core modes and Slichter modes, respectively.

However, as many geodesists have reported, local heterogeneity of media in the immediate vicinity of a site causes large variation in observed strain associated with Earth tides (for example, Bilham et al. 1974). This fact implies that strain seismograms associated with the passage of seismic waves may also be affected by local heterogeneity. Thus, it is very important to know the effects of local media on observed strain seismograms before using such records for seismological applications, including CMT inversion. In a previous report, we proposed a simple method to evaluate local effects on strain seismograms when investigating the effects at Matsushiro for a Love wave in a period range of 170 - $400 \mathrm{sec}$ (Okamoto et al. 2007). As reported, the EW and NS component strain seismograms were amplified by a factor of 1.28 and 1.83 for a Love wave, respectively.

In the present study, we investigate the local effects for a Rayleigh wave observed in a period range of $150-300 \mathrm{sec}$. The method adopted in this study is basically the same as that proposed in the previous report.

\section{POLARIZATION ANGLE}

First, we investigate the polarization angle of a strain seismogram for a long period Rayleigh wave. For a Love wave, we previously found that the amplitude ratios of the EW to NS component observed strain seismograms were 0.7 , although the theoretical value is unity (Okamoto et al. 2007). Since the amplitude ratio is a reciprocal of the tangent of the polarization angle, the result can be described as "the polarization angles of an observed strain seismogram being $55^{\circ}$ [ $=\arctan (1 / 0.7)]$, although the theoretical value is $45^{\circ}$ ". Our purpose in this section is to examine whether there exists such a deviation from a theoretical value in the polarization angle for Rayleigh waves or not.

Theoretically, the polarization angle of strain seismograms recorded by EW- and NScomponent extensometers is related to that of velocity seismograms at the same site as:

$$
\tan \theta_{s}=\tan ^{2} \theta_{v},
$$

where $\theta_{s}$ and $\theta_{v}$ respectively denote the polarization angles of strain and velocity seismograms measured counterclockwise from an easterly direction, and are assumed to be $-90^{\circ}<\theta_{s}<90^{\circ}$ and $-90^{\circ}<\theta_{v}<90^{\circ}$. Actually can $\theta_{s}$ take only values within a range of $0^{\circ}<\theta_{s}<90^{\circ}$.

Equation (1) can be easily obtained as follows: Consider a plane Rayleigh wave with an angular frequency $\omega$ traveling in a $\theta$-direction. $\theta$ is measured counterclockwise from the 
east. We take $x_{R}$-axis in the $\theta$-direction and make $x_{T}$-axis perpendicular to $x_{R}$-axis clockwise. $\omega$ is assumed very small and we consider only long-period surface waves in this study. Then the displacement field can be expressed by:

$$
\left(\begin{array}{l}
u_{R}\left(\omega, t, x_{R}\right) \\
u_{T}\left(\omega, t, x_{R}\right)
\end{array}\right)=\left(\begin{array}{c}
A_{R}(\omega) \exp \left[i\left\{\left[\omega t-k_{R}(\omega) x_{R}\right]+\phi_{R}\right\}\right] \\
0
\end{array}\right),
$$

where $u_{R}$ and $u_{T}$ denote radial and transverse component displacement, $A_{R}$ amplitude, $k_{R}$ wavenumber along the $x_{R}$-axis, and $\phi_{R}$ initial phase at $x_{R}=0$, respectively. If both a two-component seismometer and two-component extensometers are installed at the origin and in the eastwest and north-south directions, the output from the seismometer is expressed by:

$$
\left(\begin{array}{c}
v_{E}(\omega, t) \\
v_{N}(\omega, t)
\end{array}\right)=i \omega A_{R}(\omega)\left(\begin{array}{c}
\cos \theta \\
\sin \theta
\end{array}\right) \exp \left[i\left(\omega t+\phi_{R}\right)\right],
$$

where $v_{E}(\omega, t)$ and $v_{N}(\omega, t)$ denote EW- and NS- component velocity seismograms, and from equation 12 in Benioff (1935), the output from the extensometers is expressed by:

$$
\left(\begin{array}{c}
\varepsilon_{E E}(\omega, t) \\
\varepsilon_{N N}(\omega, t)
\end{array}\right)=-i k_{R}(\omega) A_{R}(\omega)\left(\begin{array}{c}
\cos ^{2} \theta \\
\sin ^{2} \theta
\end{array}\right) \exp \left[i\left(\omega t+\phi_{R}\right)\right],
$$

where $\varepsilon_{E E}(\omega, t)$ and $\varepsilon_{N N}(\omega, t)$ denote EW- and NS- component strain seismograms, respectively. The tangent of the polarization angle of velocity and strain seismograms are respectively given by:

$$
\tan \theta_{v}=v_{N} / v_{E}=\tan \theta
$$

and

$$
\tan \theta_{s}=\varepsilon_{N N} / \varepsilon_{E E}=\tan ^{2} \theta
$$

From equations (5) and (6), we finally have equation (1). In this section, we examine whether observed strain and velocity seismograms satisfy relation (1) or not.

On 28 March 2005, a very large earthquake with a moment magnitude of 8.6 occurred off the west coast of Sumatra Island, Indonesia. This earthquake, also known as the largest aftershock of the Great Sumatra-Andaman Earthquake of 26 December 2004, is quite suitable for this analysis because its focal mechanism and source-receiver azimuth, shown in Fig. 1, made the amplitude of Rayleigh waves observed at Matsushiro large and Love waves relatively small because of their radiation patterns. 


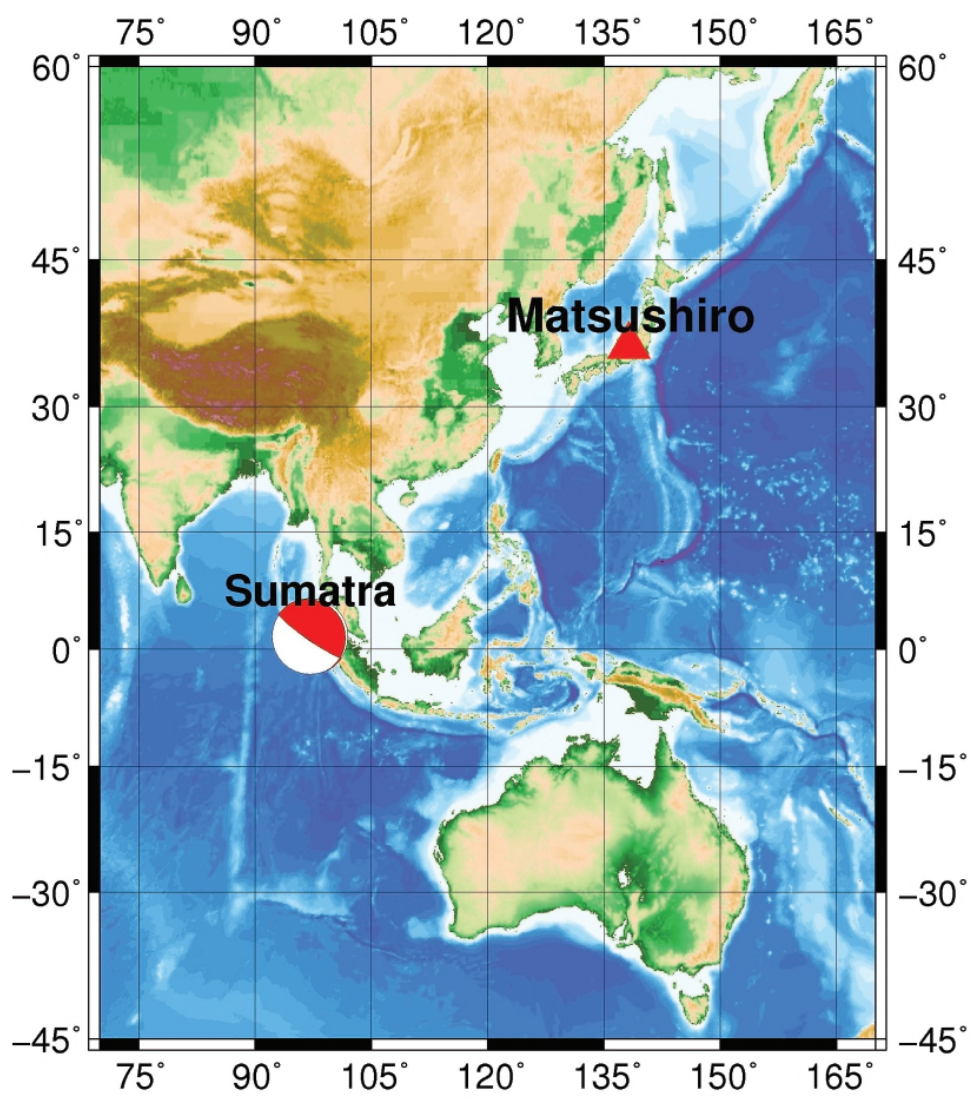

Fig. 1. Map of observation station and source of 2005 offshore west coast Sumatran Island Earthquake.

Before investigation of the polarization angles of observed strain and velocity seismograms from this earthquake, we first perform the same analysis for theoretical strain and velocity seismograms to verify the applicability of this method. The theoretical seismograms at Matsushiro are synthesized based upon the normal mode theory (Gilbert and Dziewonski 1975), by superposition of eigenfunctions with periods longer than $45 \mathrm{sec}$. The Earth model PREM (Dziewonski and Anderson 1981) and the Harvard CMT solution are adopted in the calculation. The source parameters are summarized in Table 1. It should be noted that NS and EW component strain rods at Matsushiro are respectively installed in the direction of $\mathrm{N} 2^{\circ} \mathrm{W}$ and $\mathrm{E} 2{ }^{\circ} \mathrm{N}$, as reported by Yamagishi et al. (1976). Thus NS and EW component strain seismograms are respectively calculated for extensometers polarized in the direction of $\mathrm{N} 2^{\circ} \mathrm{W}$ and $\mathrm{E} 2^{\circ} \mathrm{N}$. In addition, we have to replace equations (4) and (6) by 
Table 1. West coast offshore Sumatran Island Earthquake Harvard centroid moment tensor solution.

\begin{tabular}{ll}
\hline Date & 28 Mar. 2005 \\
Centroid Time & $16: 10: 31.5 \mathrm{UTC}$ \\
\hline Latitude & $1.67 \mathrm{~N}$ \\
Longitude & $97.07 \mathrm{E}$ \\
Depth & $25.8 \mathrm{~km}$ \\
\hline Mw & 8.6 \\
Half Duration & $49.4 \mathrm{sec}$ \\
\hline Moment Tensor & $\left(\times 10^{29}\right.$ dyne cm $)$ \\
$M_{r r}$ & 0.266 \\
$M_{\theta \theta}$ & -0.114 \\
$M_{\phi \phi}$ & -0.153 \\
$M_{r \theta}$ & 0.839 \\
$M_{r \phi}$ & -0.568 \\
$M_{\theta \phi}$ & 0.148 \\
\hline
\end{tabular}

$$
\left(\begin{array}{c}
\varepsilon_{E E}(\omega, t) \\
\varepsilon_{N N}(\omega, t)
\end{array}\right)=-i k_{R}(\omega) A_{R}(\omega)\left(\begin{array}{c}
\cos ^{2}\left(\theta-2^{\circ}\right) \\
\sin ^{2}\left(\theta-2^{\circ}\right)
\end{array}\right) \exp \left[i\left(\omega t+\phi_{R}\right)\right],
$$

and

$$
\tan \theta_{s}=\varepsilon_{N N} / \varepsilon_{E E}=\tan ^{2}\left(\theta-2^{\circ}\right),
$$

respectively. From equations (5) and (8), we have

$$
\tan \theta_{s}=\tan ^{2}\left(\theta_{v}-2^{\circ}\right),
$$

instead of relation (1).

Figures 2a - c show spectrograms for the EW and NS component theoretical strain seismograms produced by the multiple filter technique (Dziewonski et al. 1969), and the arctangent of their amplitude ratio, respectively. Theoretical dispersion curves for fundamental mode Rayleigh waves are also plotted. Note that the arctangent of the amplitude ratio of the NS to EW component in Fig. 2c corresponds to the polarization angle measured counterclockwise 
from the direction of the EW component strain rod. This can be shown as follows: From equation (7), the theoretical strain seismograms, consisting of various frequency contents, can be expressed by:

$$
\left(\begin{array}{c}
\varepsilon_{E E}(t) \\
\varepsilon_{N N}(t)
\end{array}\right)=-i\left(\begin{array}{c}
\cos ^{2}\left(\theta-2^{\circ}\right) \\
\sin ^{2}\left(\theta-2^{\circ}\right)
\end{array}\right) \int_{-\infty}^{\infty} k_{R}(\omega) A_{R}(\omega) \exp \left[i\left(\omega t+\phi_{R}\right)\right] d \omega .
$$

In equation (10), the fact that the ratio of NS to EW component strains is $\tan ^{2}\left(\theta-2^{\circ}\right)$ is important. By applying a narrow band-pass filter with a center angular frequency of $\omega$ to the strain seismograms (10), we obtain spectrograms expressed by:

$$
\left(\begin{array}{c}
\left|\varepsilon_{E E}(\omega, t)\right| \\
\left|\varepsilon_{N N}(\omega, t)\right|
\end{array}\right)=B_{R}(\omega, t)\left(\begin{array}{c}
\cos ^{2}\left(\theta-2^{\circ}\right) \\
\sin ^{2}\left(\theta-2^{\circ}\right)
\end{array}\right)
$$
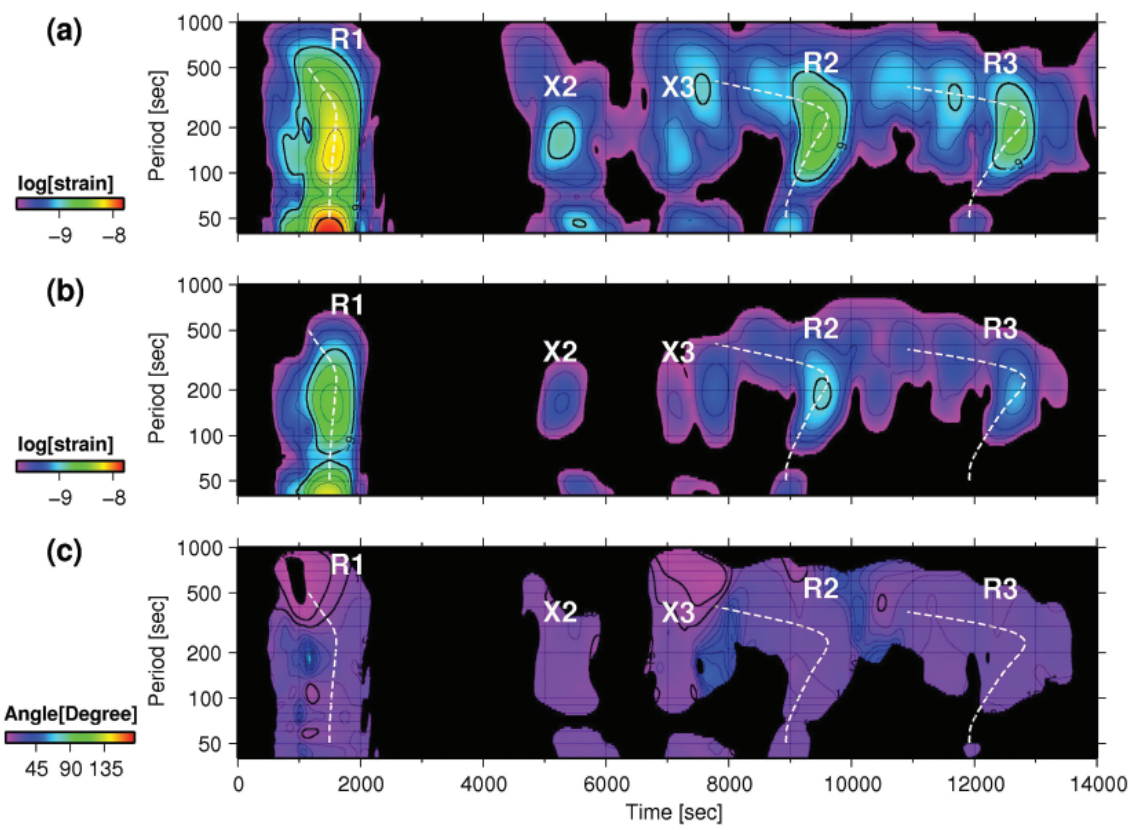

Fig. 2. Spectrograms for (a) EW and (b) NS component theoretical strain seismograms at Matsushiro for the 2005 offshore west coast Sumatran Island Earthquake, and (c) arctangent of amplitude ratio of the NS to EW component. The time is measured from 161031 UT 28 March 2005 (corresponding to the centroid time). White curves denote theoretical dispersion curves for fundamental mode Rayleigh waves in PREM. 
where $\left|\varepsilon_{E E}(\omega, t)\right|$ and $\left|\varepsilon_{N N}(\omega, t)\right|$ denote spectrograms for EW and NS component strain seismograms, and $B_{R}(\omega, t)$ the instantaneous amplitude of the radial component strain seismogram, respectively. Note that the ratio of NS to EW component spectrograms is $\tan ^{2}\left(\theta-2^{\circ}\right)$ again. From equations (8) and (11), it follows that:

$$
\theta_{s}=\arctan \left[\tan ^{2}\left(\theta_{v}-2^{\circ}\right)\right]=\arctan \left[\left|\varepsilon_{N N}(\omega, t)\right| /\left|\varepsilon_{E E}(\omega, t)\right|\right]
$$

which means that the arctangent of amplitude ratio of the NS to EW component in Fig. 2c corresponds to the polarization angle measured counterclockwise from the direction of the EW component strain rod.

Figure 3 plots cross-sections of Fig. 2c along the dispersion curves for R1 to R3 phases, showing that polarization angles for the theoretical strain seismogram measured from the direction of the EW component strain rod are $20^{\circ}$ in the period range of $50-300 \mathrm{sec}$.

Figures 4 and 5 are the same plot as Figs. 2 and 3 for theoretical velocity seismograms, respectively. As shown in Fig. 5, polarization angles for the theoretical velocity seismogram are $\mathrm{E} 33^{\circ} \mathrm{N}$ in the period range of $50-300 \mathrm{sec}$, corresponding to the radial direction, and we have $\tan \theta_{s}=\tan ^{2}\left(\theta_{v}-2^{\circ}\right)$ as we expected. The fluctuation in the polarization angles of R1 phase seen in Figs. 3 and 5 would be due to contamination of the Love wave, because G1 and R1 phases arrive at almost the same time.

Observed strain seismograms, shown in Fig. 6, and velocity seismograms, shown in Fig. 7, are analysed in the same way. Figures 8 and 9 are the same plots as Figs. 2 and 4 for observed

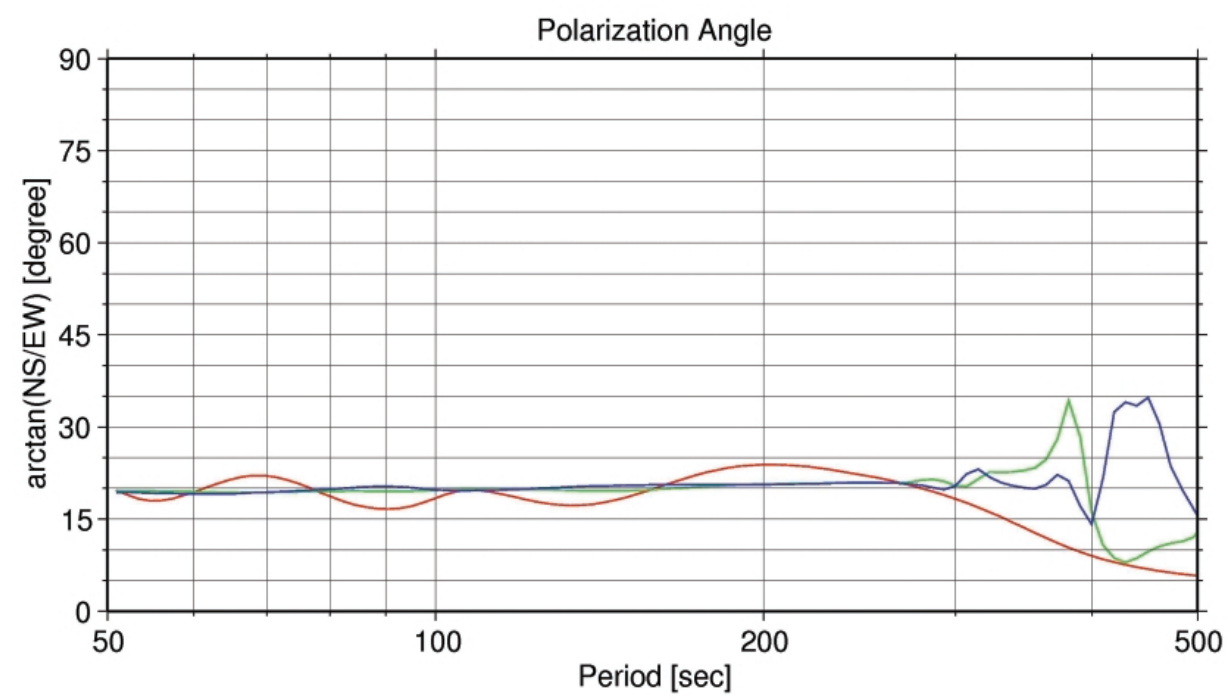

Fig. 3. Cross-sections of spectrograms in Fig. 2c along the dispersion curves for R1 (red), R2 (green), and R3 (blue) phases. 

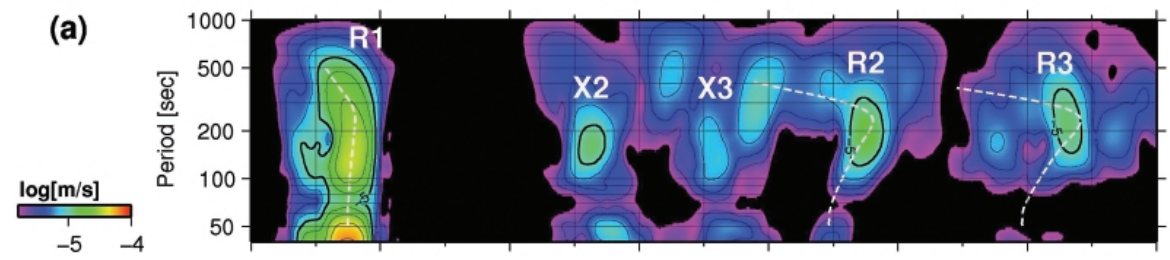

(b)
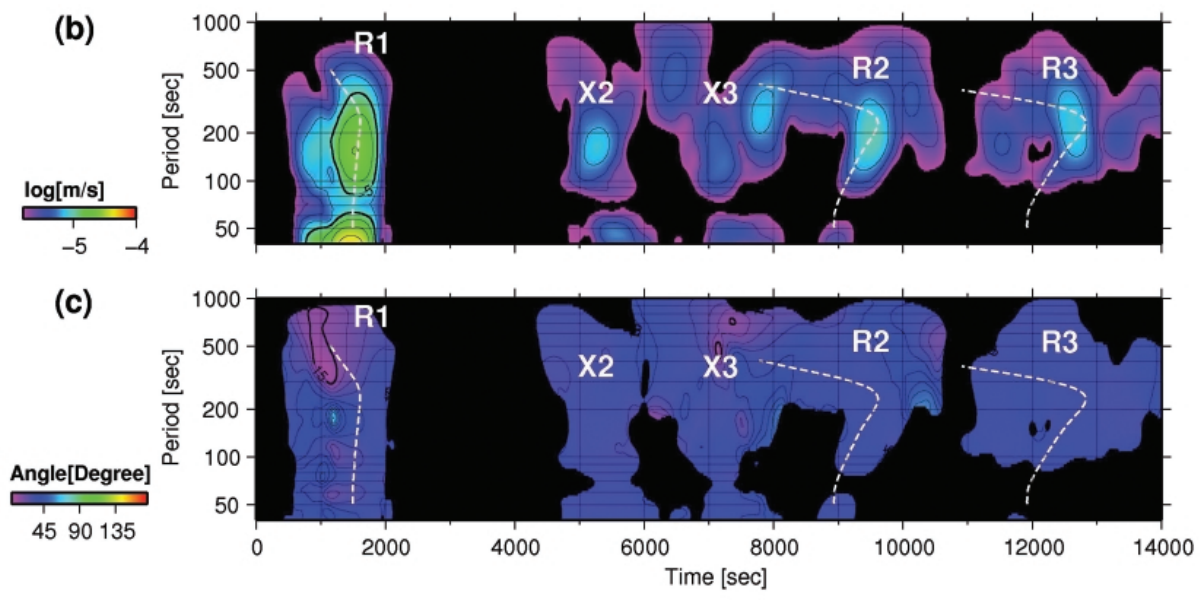

Fig. 4. The same as Fig. 2 for theoretical velocity seismograms.

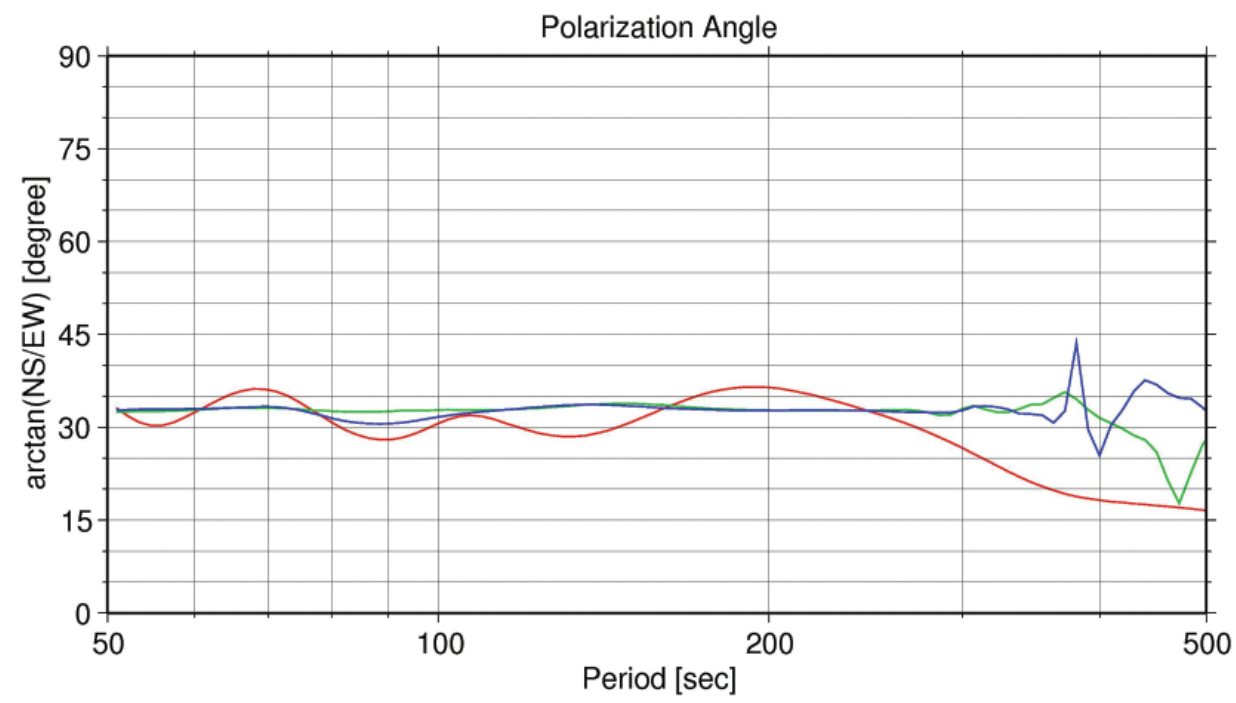

Fig. 5. Cross-sections of spectrograms in Fig. 4c along the dispersion curves for R1 (red), R2 (green), and R3 (blue) phases. 
(a)

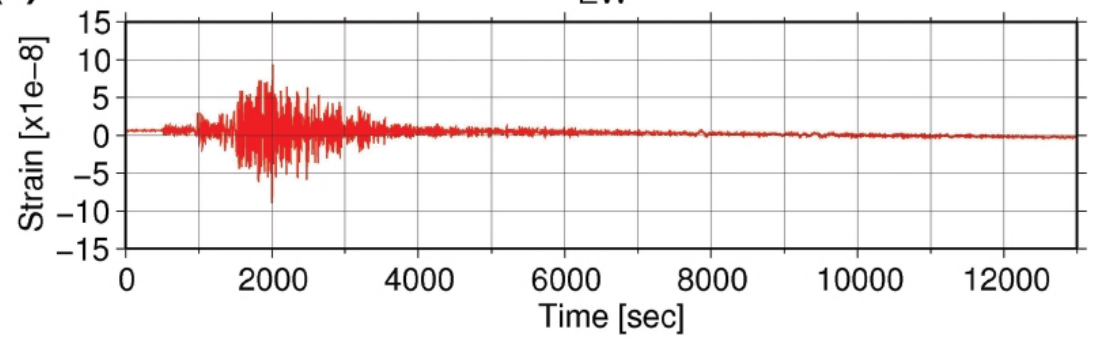

(b)

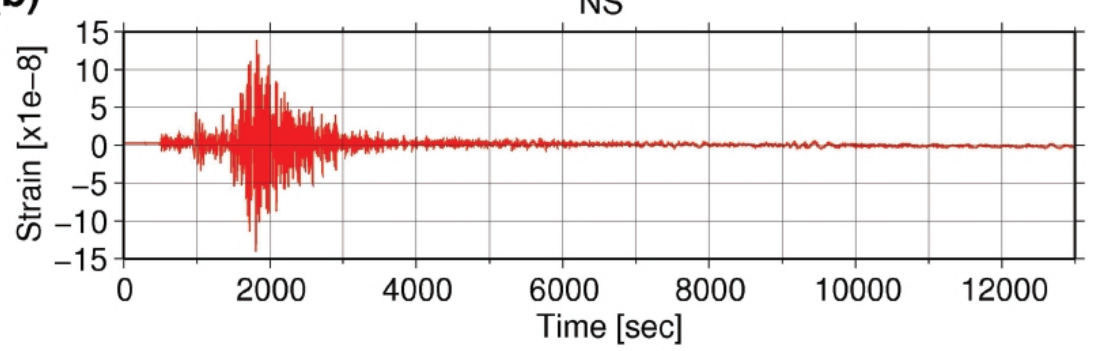

Fig. 6. Observed strain seismograms at Matsushiro from the 2005 offshore west coast Sumatran Island Earthquake. (a) EW and (b) NS component. The time is the same as Fig. 2.

(a)

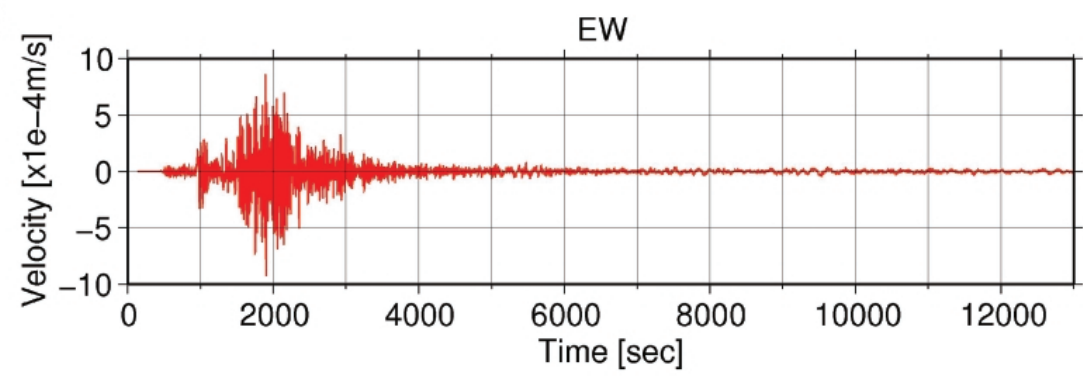

(b)

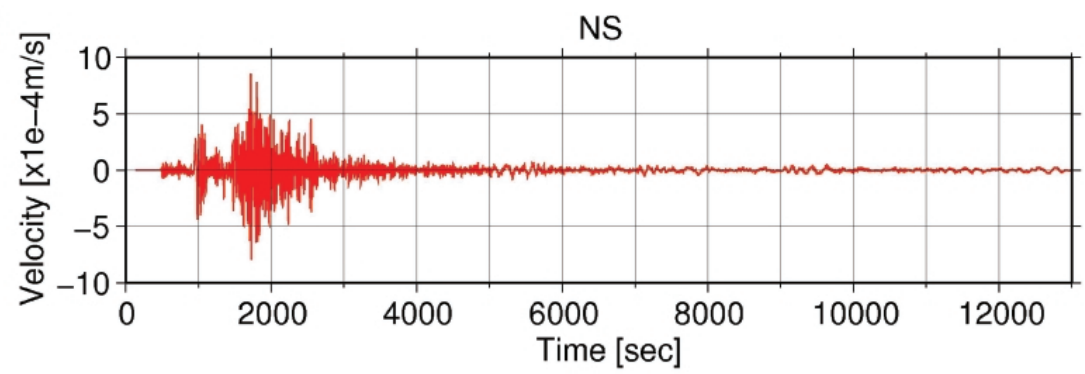

Fig. 7. The same as Fig. 6 for observed velocity seismograms. 

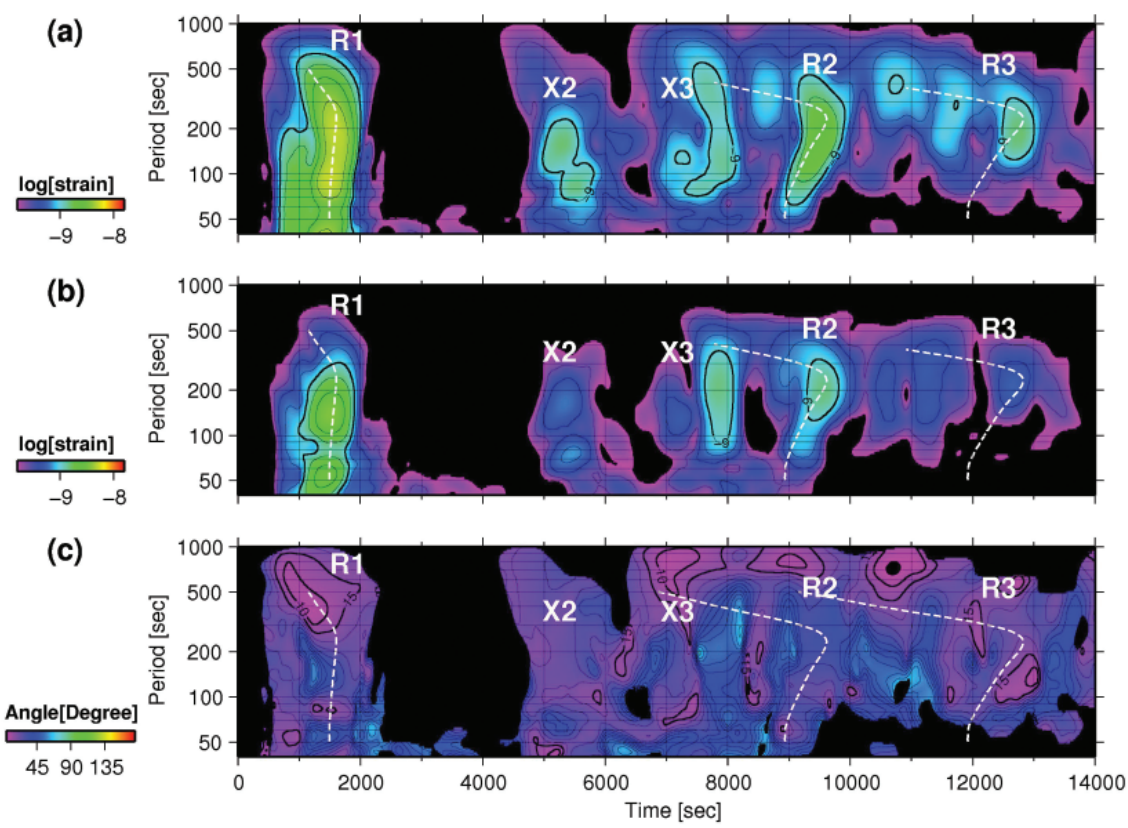

Fig. 8. The same as Fig. 2 for observed strain seismograms.
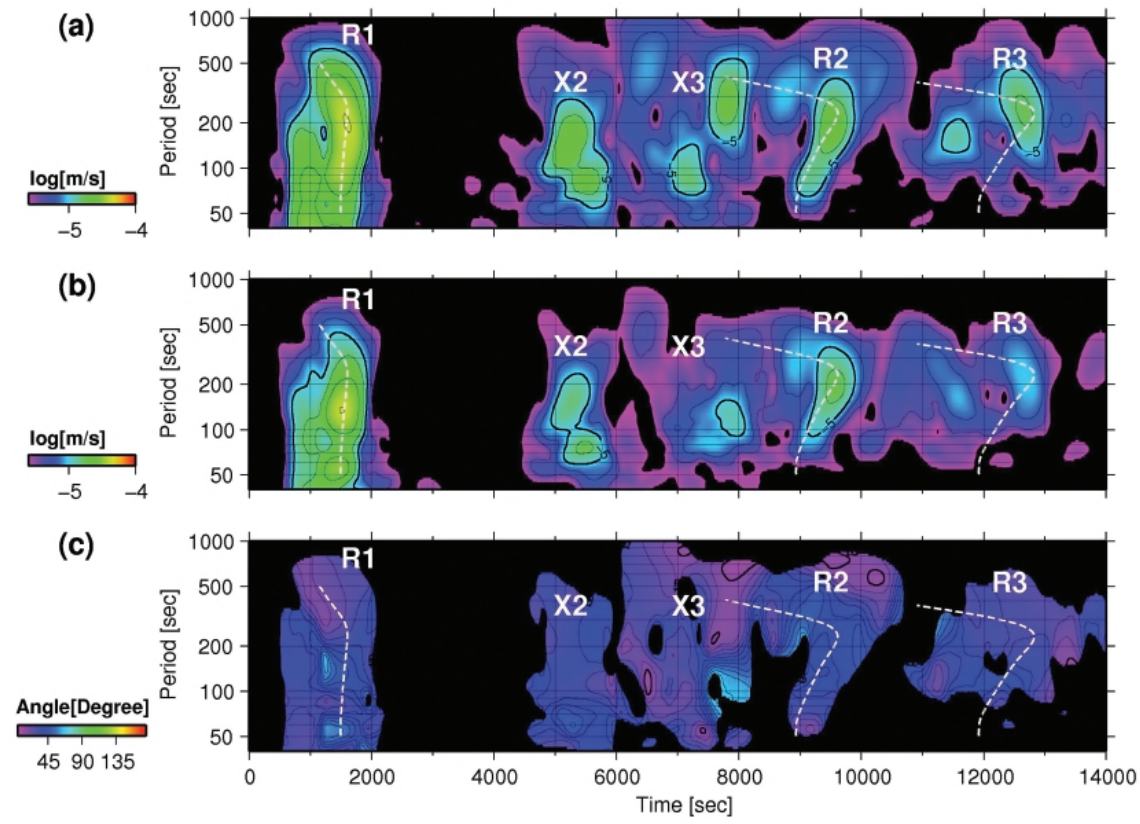

Fig. 9. The same as Fig. 2 for observed velocity seismograms. 
strain and velocity seismograms, respectively. The polarization angles of R1 to R3 phases for observed strain and velocity seismograms are tabulated in Table 2. Again taking the declination of two degrees into account, we find that every pair of polarization angles satisfies the relation $\tan \theta_{s}=\tan ^{2}\left(\theta_{v}-2^{\circ}\right)$. Thus polarization angles of strain seismograms for a Rayleigh wave do not depart from the expected ones from velocity seismograms, in contrast to the Love wave case.

For a Love wave, however, we found deviation from theoretical value not only in the polarization angle but also in the amplitude ratio of velocity to strain (Okamoto et al. 2007). The amplitude ratio for a Rayleigh wave will be investigated in the following section.

\section{LOCAL PHASE VELOCITY}

Intercomparison of records from strain and velocity seismographs installed at a single station give local phase velocities of seismic waves (Mikumo and Aki 1964). And if both strain and velocity seismograms have not been affected by local geology, the obtained phase velocities should agree with theoretical values. In the Love wave case, the estimated local phase velocity at Matushiro was $22 \%$ smaller than the theoretical value, suggesting that the observed strain had been amplified by local geology structure (Okamoto et al. 2007).

Here, we apply the method to Rayleigh waves. First, however, as with our previous study, theoretical seismograms are analysed to confirm the applicability of the method. Figures $10 \mathrm{a}-\mathrm{c}$ show spectrograms for $\partial u_{R} / \partial t$ calculated from theoretical velocity seismograms, $\partial u_{R} / \partial x_{R}$ from theoretical strains, and their amplitude ratio which should correspond to local phase velocities of Rayleigh waves, respectively, where $u_{R}$ denotes a radial component displacement field, $x_{R}$ the direction of wave propagation, and $t$ time (for more detail, refer to Okamoto et al. 2007).

Figure 11 plots cross-sections of Fig. 10c along the dispersion curves for R1 and R2 phases. As we expected, the estimated phase velocity from the theoretical seismograms is consistent with the theoretical value in the period range of $50-500 \mathrm{sec}$ for R1 and $50-300 \mathrm{sec}$ for R2.

Observed strain and velocity seismograms are analysed in the same way. Figure 12 is the same plot as Fig. 10 for observed seismograms. The velocity seismograms have been corrected for instrumental response.

Table 2. The polarization angles of R1, R2, and R3 phases for observed strain and velocity seismograms. The angles are measured counterclockwise from the direction of $\mathrm{E} 2^{\circ} \mathrm{N}$ for strain and $\mathrm{E} 0^{\circ} \mathrm{N}$ for velocity.

\begin{tabular}{lccc}
\hline Phase & R1 & R2 & R3 \\
\hline Strain & $9^{\circ}$ & $32^{\circ}$ & $17^{\circ}$ \\
Velocity & $23^{\circ}$ & $40^{\circ}$ & $31^{\circ}$ \\
\hline
\end{tabular}



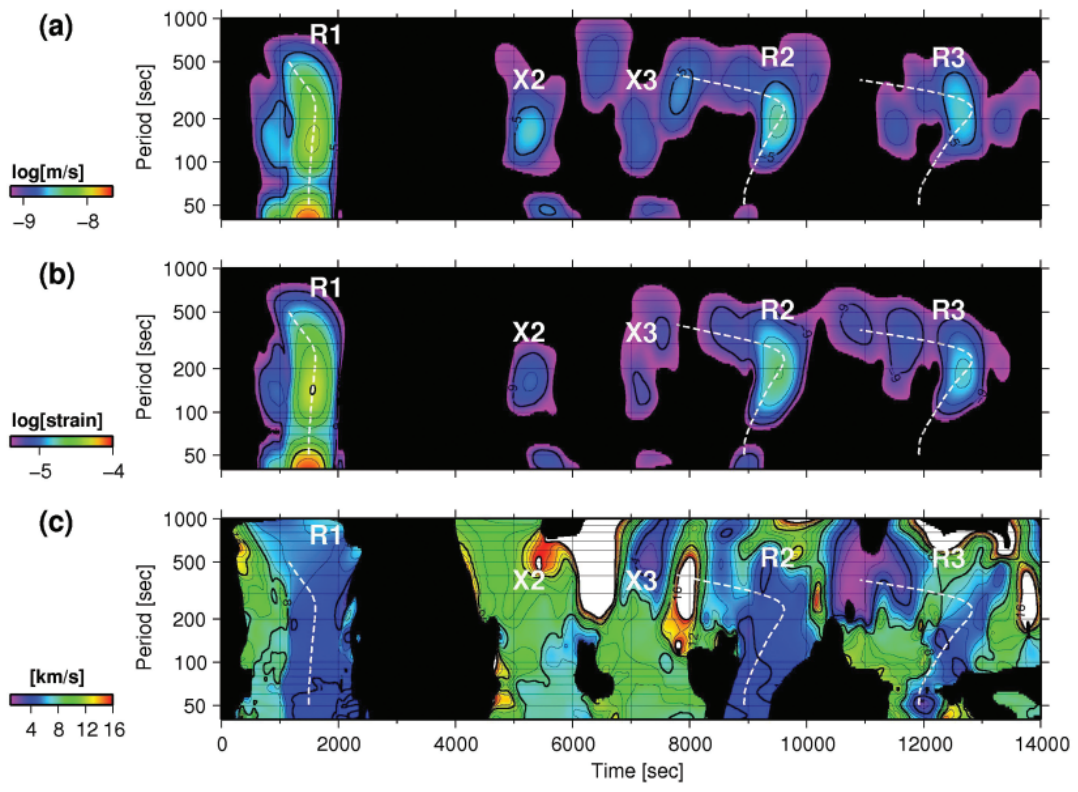

Fig. 10. Spectrograms for (a) $\partial u_{R} / \partial t$ and (b) $\partial u_{R} / \partial x_{R}$ calculated from the theoretical velocity and strain seismograms at Matsushiro for the 2005 offshore west coast Sumatran Island Earthquake, and (c) the ratio of $\partial u_{R} / \partial t$ to $\partial u_{R} / \partial x_{R}$. The time and white curves are the same as in Fig. 2.

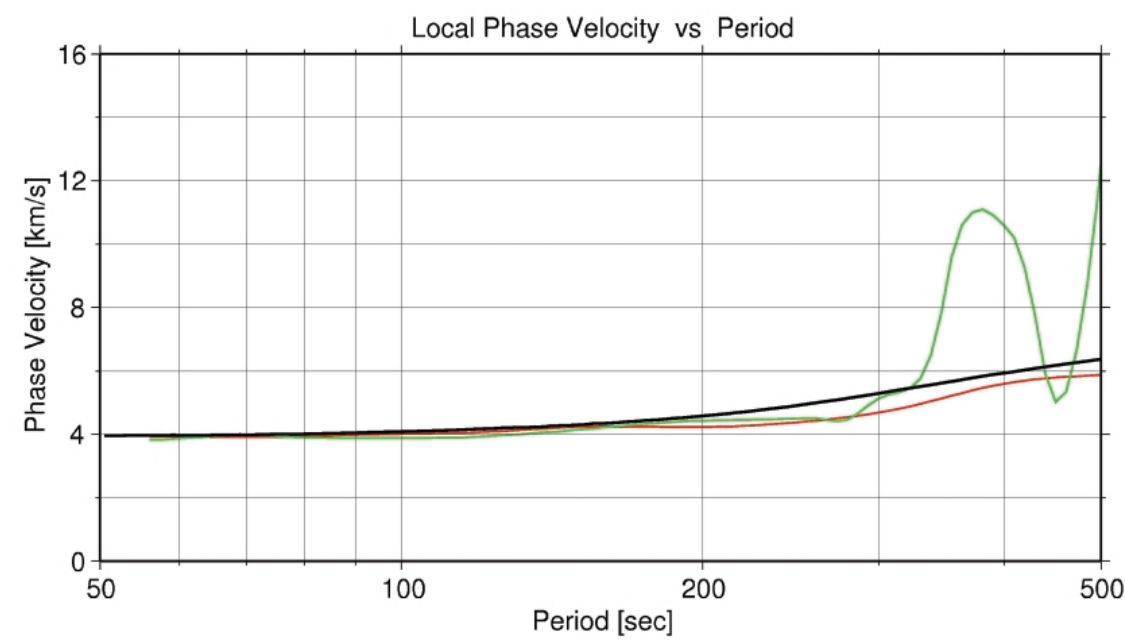

Fig. 11. Cross-sections of Fig. 10c along the dispersion curves for R1 (red) and R2 (green) phases. The black curve denotes the theoretical phase velocity for the fundamental mode Rayleigh wave in PREM. 

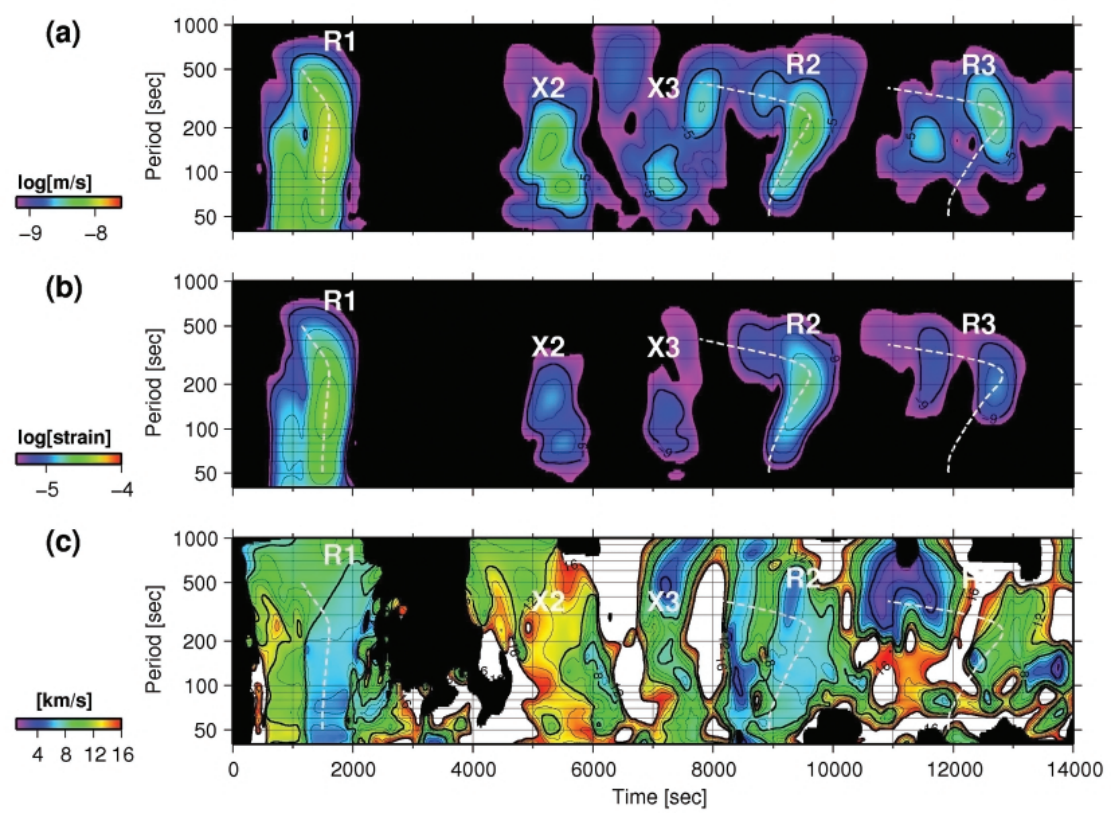

Fig. 12. The same as Fig. 10 for observed velocity and strain seismograms.

Figure 13 plots cross-sections of Fig. 12c along the dispersion curves for R1 and R2 phases, showing that the estimated local phase velocity from the observed seismograms is approximately 54\% larger than the theoretical value, in contrast to the result for the theoretical seismogram. It seems that the factor $(54 \%)$ is independent of the period for the period range 150 - $300 \mathrm{sec}$.

Fluctuation in the estimated phase velocities of R2 phase seen in Figs. 11 and 13 is due to two technical difficulties. One was strong dispersion of the Rayleigh wave when the period longer than $300 \mathrm{sec}$. In such cases, plotting energy distribution for strongly dispersed waves is quite difficult, and not only peaks but also troughs appear along dispersion curves. The other was the small amplitude of the R2 phase when the period was shorter than $130 \mathrm{sec}$. The phase velocities in the Figs. 11 and 13 have been estimated by taking the amplitude ratio of velocity to strain spectrograms, and the ratio tends to be quite unstable when the denominator is small.

Figures 14 and 15 show results for two other earthquakes: the Timor Earthquake of 11 November 2004 and the Carlsberg Ridge Earthquake of 15 July 2003, respectively. Both figures show almost the same result for the Sumatra Earthquake (Fig. 13), implying that local effects are independent of the wave propagation direction.

It follows from this result that both EW and NS component strain seismograms for a Rayleigh wave have been reduced by $35 \%(1 / 1.54=0.65)$ in amplitude, unless velocity seismograms have been affected by local geology structure. The local effects on velocity seismograms will be examined in the following section. 


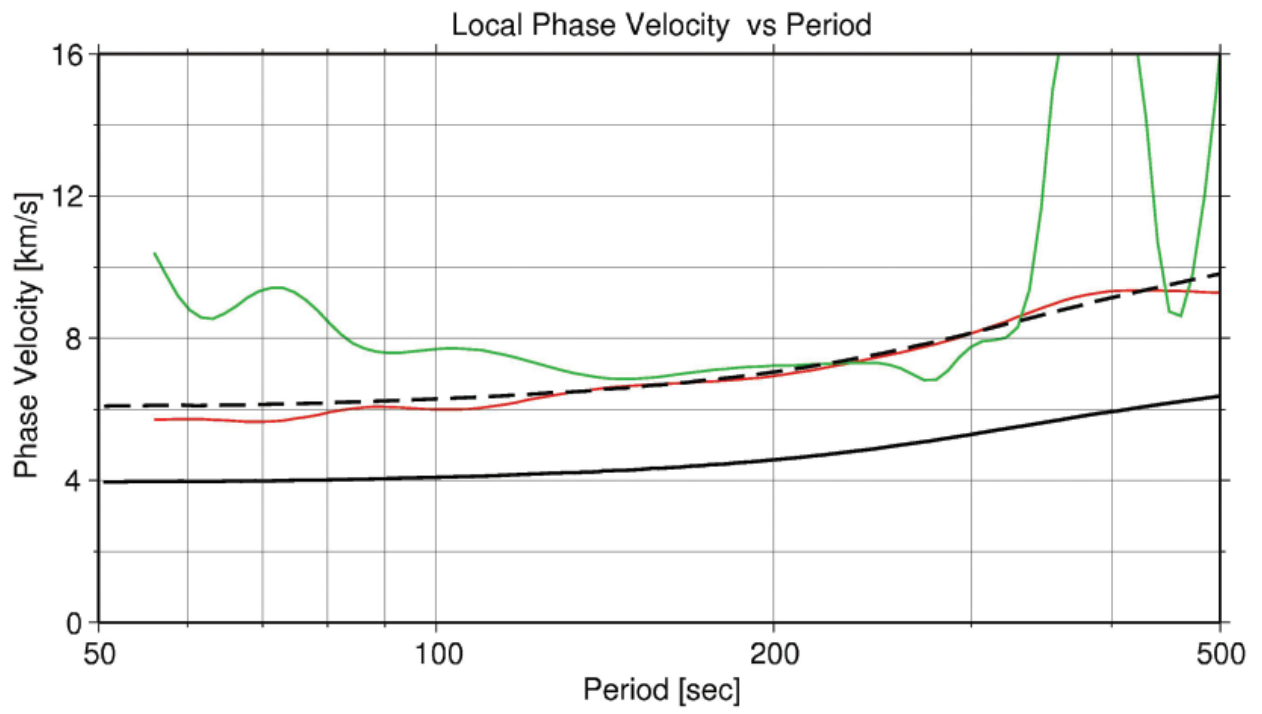

Fig. 13. Cross-sections of Fig. 12c along the dispersion curves for R1 (red) and R2 (green) phases. The solid black curve is the same as in Fig. 11. The dotted black curve is the theoretical phase velocity multiplied by 1.54 .

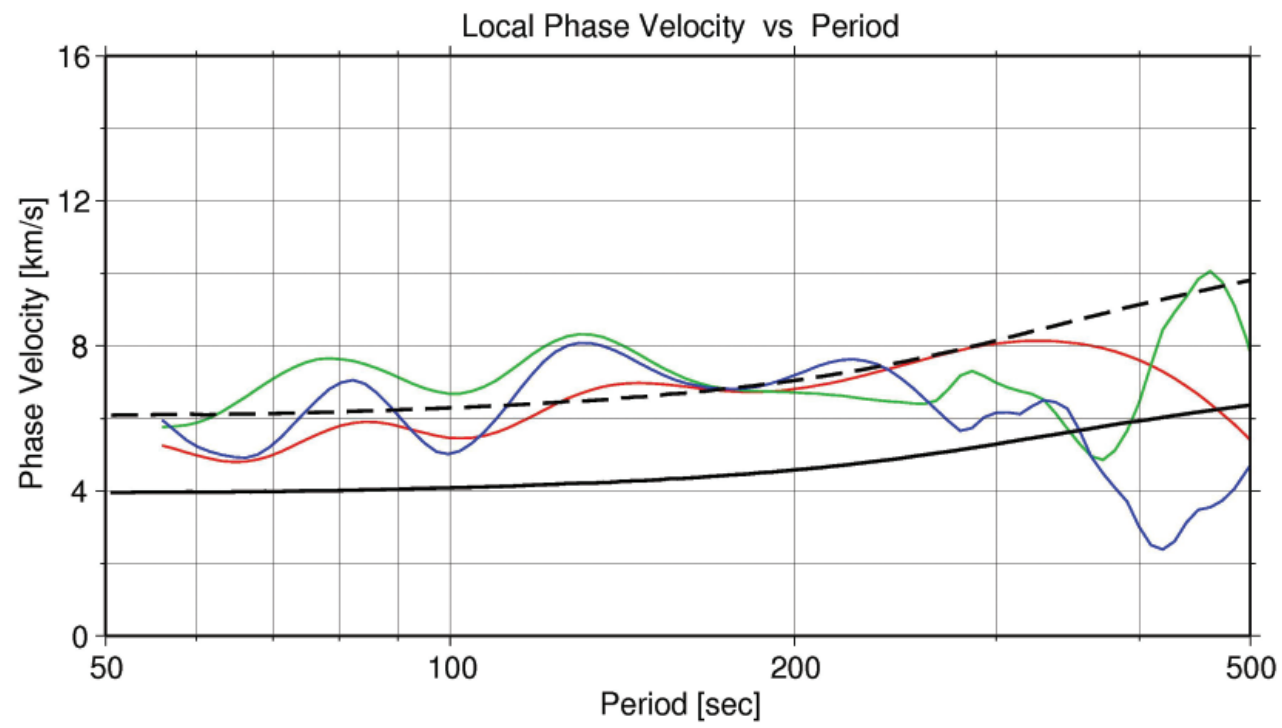

Fig. 14. Cross-sections of the spectrogram ratio of $\partial u_{R} / \partial t$ to $\partial u_{R} / \partial x_{R}$ along the dispersion curves for R1 (red), R2 (green) and R3 (blue) phases for the Timor Earthquake of 11 November 2004. The solid and dotted black curve is the same as in Fig. 13. 


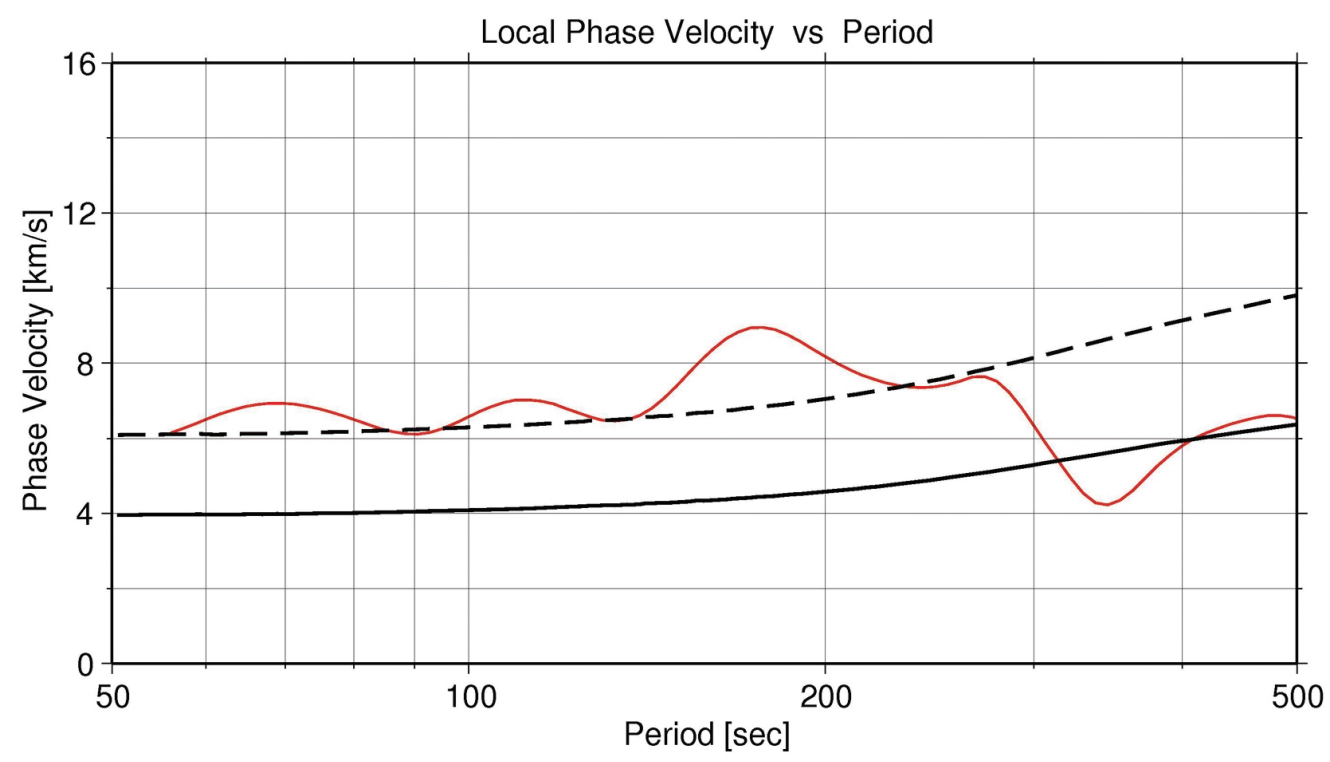

Fig. 15. Cross-sections of the spectrogram ratio of $\partial u_{R} / \partial t$ to $\partial u_{R} / \partial x_{R}$ along the dispersion curves for the R1 phase for the Carlsberg Ridge Earthquake of 15 July 2003. The solid and dotted black curve is the same as in Fig. 13.

\section{COMPARISON OF VELOCITY SEISMOGRAM WITH OTHER SEISMOGRAMS AT F-NET STATIONS}

In this section, we compare the velocity seismogram observed at Matsushiro with those observed at F-net (Okada et al. 2004) stations near Matsushiro to investigate local effects on observed velocity seismograms.

Figure 16 is a map of observation stations used. At all stations, velocity seismograms have been recorded by STS-1 broadband seismometers. All stations have nearly the same epicentral distance and azimuth from the epicenter as Matsushiro (every deviation from Matsushiro is less than 4\%), and differences in radiation pattern and distance attenuation are very small.

Figures 17 and 18 show cross-sections of spectrograms for the radial component of theoretical (Fig. 17) and observed (Fig. 18) velocity seismograms at Matsushiro and F-net stations along the dispersion curves for R1 and R2 phases. In Fig. 17, all spectra have nearly the same amplitudes in the period range of $50-500 \mathrm{sec}$. Although the velocity spectra observed at different stations have slightly different amplitudes (Fig. 18), the spectrum at Matsushiro is almost the same in amplitude as an average of those at F-net stations and every deviation from Matsushiro is less than $15 \%$ in the period range of $100-500 \mathrm{sec}$. Thus we consider the velocity seismograms observed at all observation stations, including Matsushiro, to have not been affected. 


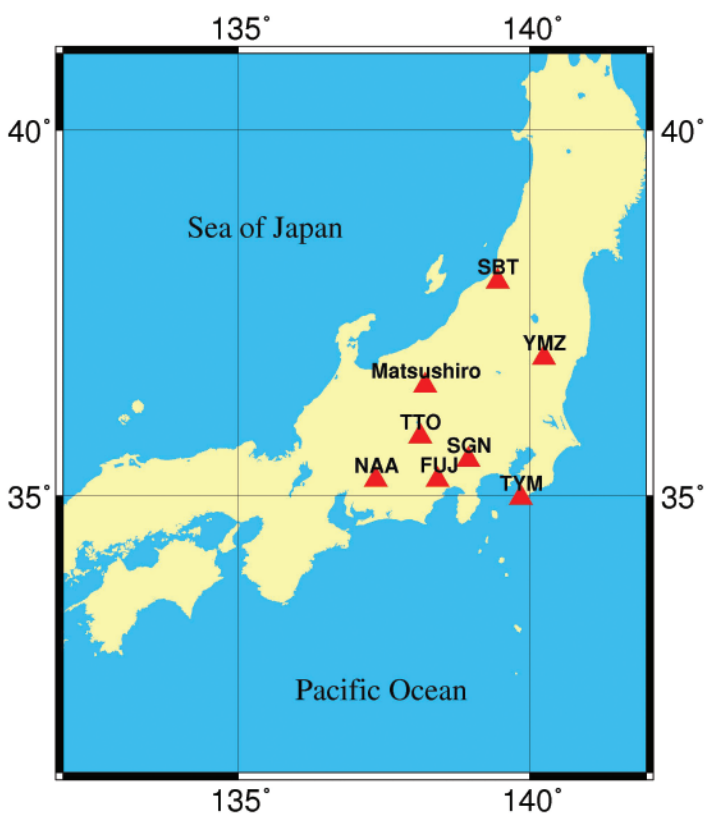

Fig. 16. Map of the observation stations.

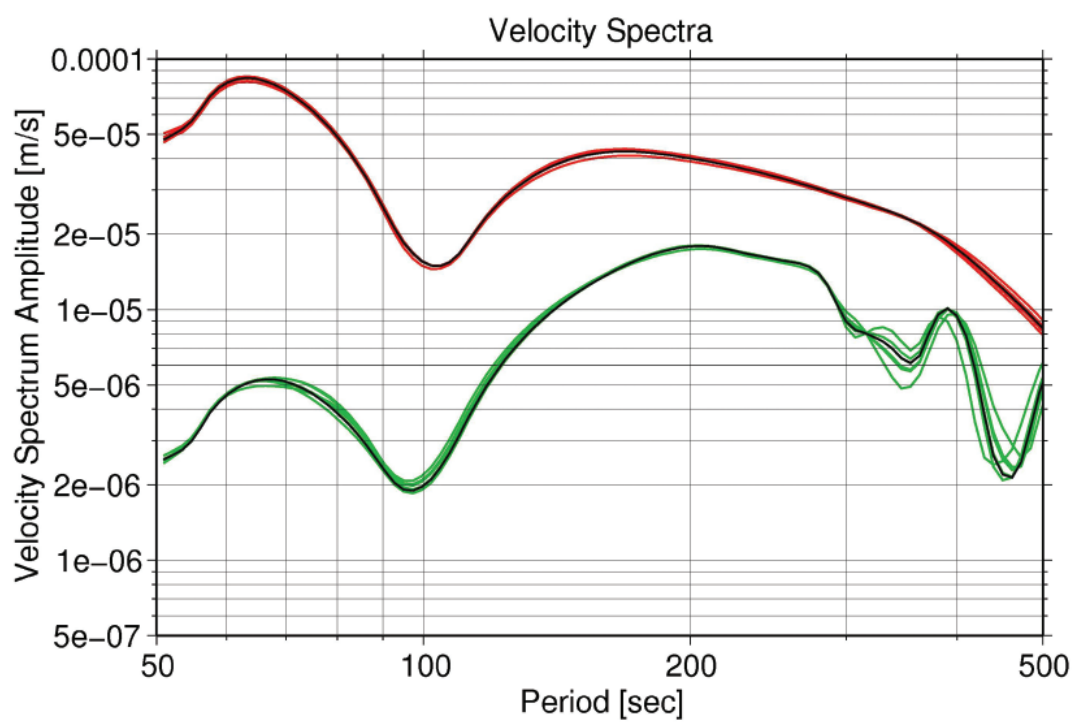

Fig. 17. Cross sections of spectrograms for $\partial u_{R} / \partial t$ calculated from theoretical velocity seismograms at Matsushiro (black) and F-net stations (coloured) along the dispersion curves for R1 (red) and R2 (green) phases. 


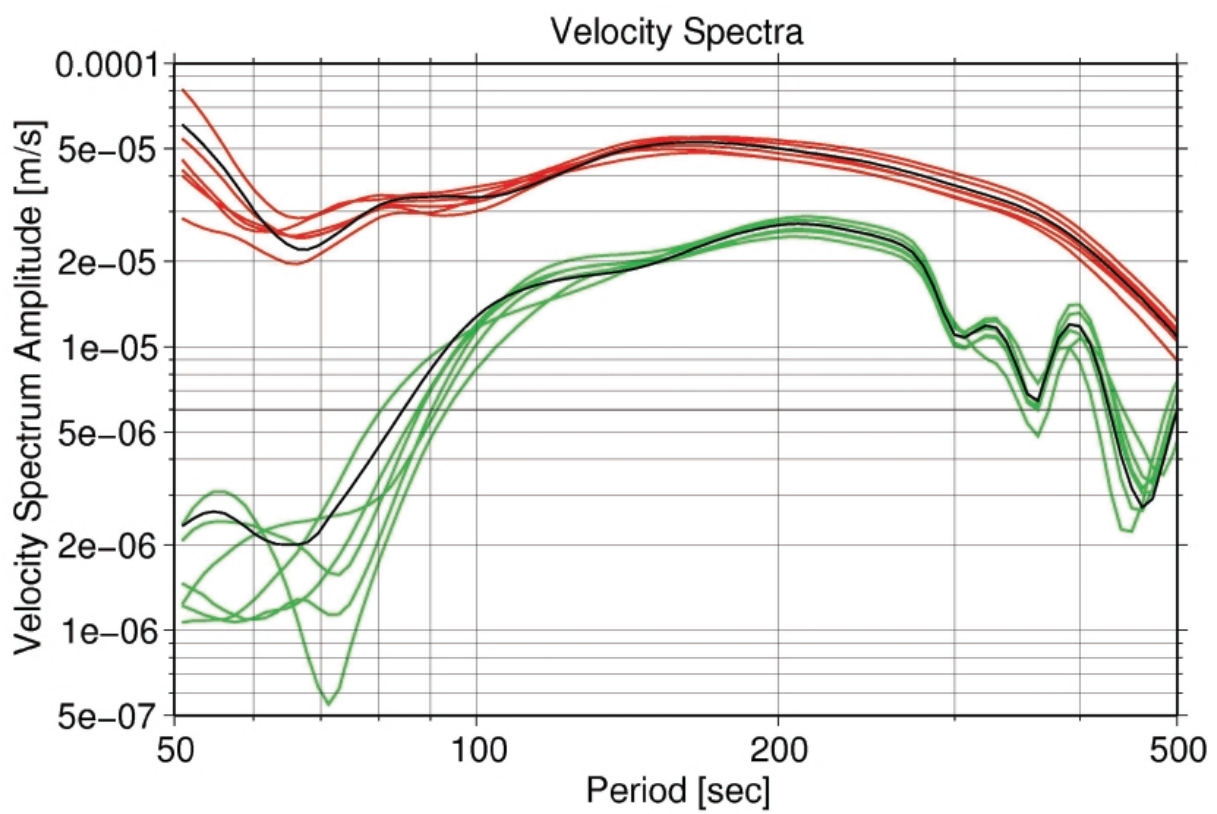

Fig. 18. The same as Fig. 17 for observed velocity seismograms.

\section{COMPARISON WITH THE THEORETICAL STRAIN SEISMOGRAM}

The results obtained from the above analyses in the period range of $150-300 \mathrm{sec}$ are summarized as follows:

1. Polarization angles of the strain seismogram agree with expected ones from the velocity seismogram.

2. Amplitude ratio of velocity to strain is $54 \%$ larger than the theoretical value.

3 . The above factor $(54 \%)$ is independent of period.

4. Velocity seismograms are nearly unaffected by local structure.

From these results, it follows that both EW- and NS-component observed strains should be multiplied by a factor of 1.54 , to remove the local effects. In this section, we finally compare observed strain seismograms before and after correction with theoretical strain seismograms to check the accuracy of the factors.

Figures 19 and 20 show the theoretical and observed strain seismograms. All seismograms have been filtered in the period range of 171 - $400 \mathrm{sec}$. In Fig. 20, the theoretical strain seismograms have been divided by 1.54, unlike the case of Fig. 19. In Fig. 20, the observed and theoretical seismograms are in good agreement, whereas in Fig. 19, the observed seismograms have remarkably smaller amplitudes than the theoretical strains. Note that the above factors are not what were determined to match these waveforms. 

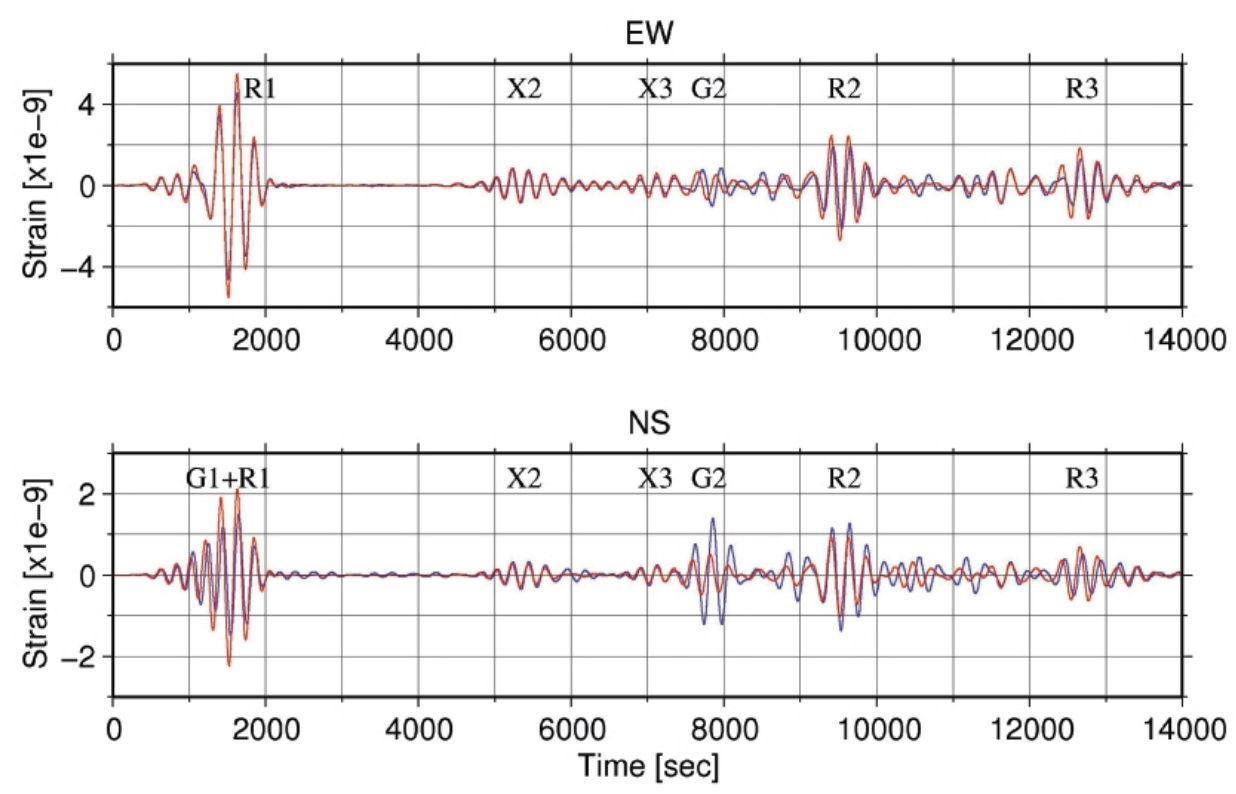

Fig. 19. Theoretical (red) and observed (blue) strain seismograms. (a) EW and (b) NS component. All seismograms have been filtered in the period range of $171-400 \mathrm{sec}$.
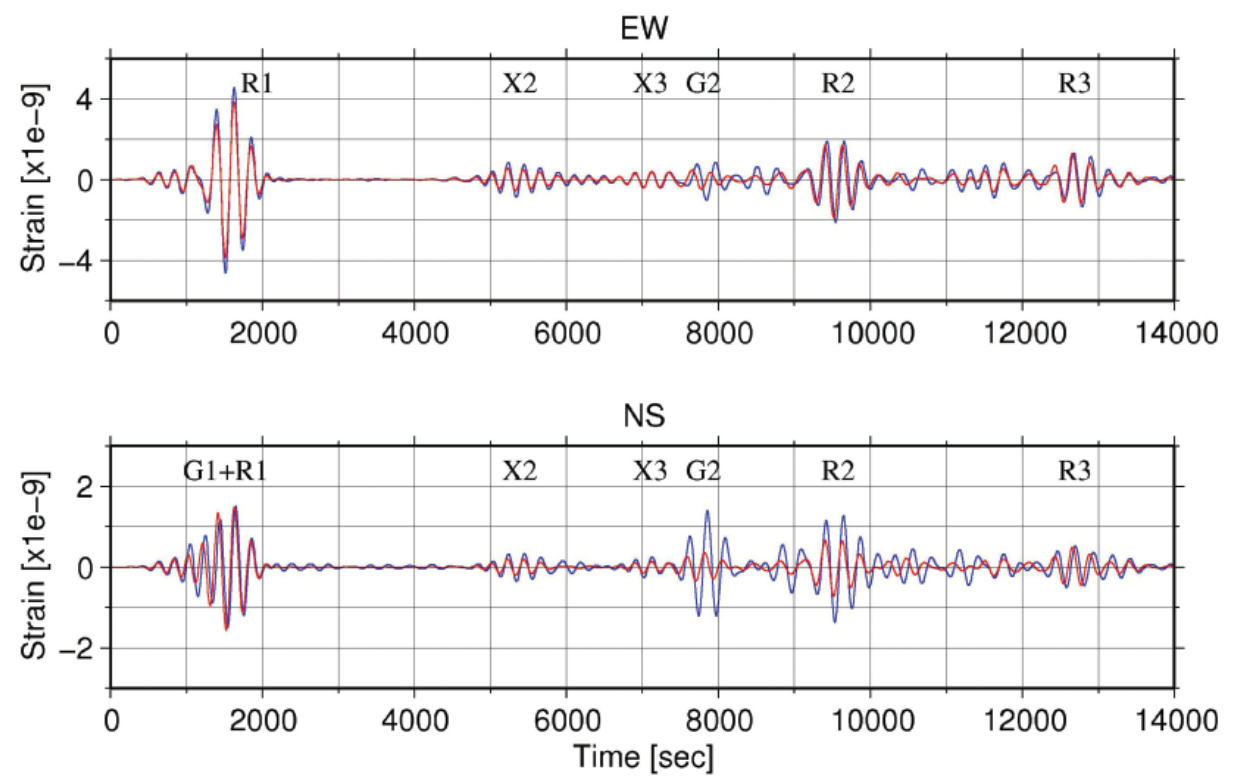

Fig. 20. The same as Fig. 19. Both theoretical strain seismograms have been divided by a factor of 1.54 . 
This comparison also indicates that local effects must be removed from observed strain seismograms before we use the observed strain seismogram for seismological analyses, and that the above factors are practical enough for the correction.

\section{SUMMARY}

We evaluated local effects on strain seismograms observed at Matsushiro for a Rayleigh wave in a period range of $150-300 \mathrm{sec}$.

First, we investigated polarization angles for a Rayleigh wave. The polarization angles agreed with the expected ones from those of velocity seismograms also observed at Matsushiro.

Next, we compared the strain seismogram with a velocity seismogram recorded with an STS-1 broadband seismometer. A ratio of a partial derivative of a displacement field with respect to time to that with respect to wave propagation direction equals a phase velocity of the wave theoretically. Utilizing this fact, we estimated the phase velocity of a Rayleigh wave using the observed velocity and strain seismogram. The result was 54\% larger than the theoretical phase velocity.

Finally, we compared the velocity seismogram with other velocity seismograms recorded by STS-1 broadband seismometers at F-net observation stations near Matsushiro, finding that every deviation from Matsushiro was less than $15 \%$.

From these results, we conclude that both the EW- and NS- component strain seismograms have been reduced by $35 \%$ for a Rayleigh wave.

It is already known that near-station heterogeneities may cause magnification of strain in amplitude. For example, Taniguchi and Oike (1984) investigated distribution of strain change in an observational tunnel caused by a Rayleigh wave and by Earth tides, by extensometers installed across a fracture zone of the Yamasaki Fault, finding that the strain amplitude at the fracture zone was approximately twice as large as that at the neighboring bedrock. Local effects on strain seismograms at hard rock site, however, have never been quantitatively evaluated. As improbable as it may sound, the local effects for Rayleigh waves are quite different from those for Love waves even when the period is the same.

Presently, there are a lot of extensometers and borehole-type strainmeters installed and in operation all over the world. The strainmeters, having a good frequency response up to the DC component, can be used as very broadband seismometers if the output signals are sampled at high frequency. As is made clear in this study, however, strainmeters have a predisposition to be affected by local geology structure, and investigation and quantitative evaluation of the local effects are required for any strain records observed at stations prior to using the records for seismological applications. Our method paves the way for the application of strain records in seismology.

Acknowledgements The authors appreciate Dr. Ruey-Der Hwang and an anonymous reviewer's comments which have considerably improved the quality of our paper. The broadband velocity seismograms used in this study were provided by the Incorporated Research Institutions for Seismology and the National Research Institute for Earth Science and Disaster Prevention. The fortran source code to synthesize theoretical seismograms was provided by 
Dr. Osamu Kamigaichi, Japan Meteorological Agency. Figures have been prepared with the GMT package provided by Wessel and Smith (1995).

\section{REFERENCES}

Benioff, H., 1935: A linear strain seismograph. Bull. Seismol. Soc. Am., 25, 283-309.

Bilham, R. G., G. C. P. King, and D. P. McKenzie, 1974 : Inhomogeneous tidal strains in Queensbury tunnel, Yorkshire. Geophys. J. Roy. Astr. Soc., 37, 217-227.

Dziewonski, A., S. Bloch, and M. Landisman, 1969: A Technique for the analysis of transient seismic signals. Bull. Seismol. Soc. Am., 59, 427-444.

Dziewonski, A. M., and D. L. Anderson, 1981: Preliminary reference Earth model. Phys. Earth Planet. Inter., 25, 297-356.

Gilbert, F., and A. M. Dziewonski, 1975: An application of normal mode theory to the retrieval of structural parameters and source mechanisms from seismic spectra. Phil. Trans. Roy. Soc. London., A278, 187-269.

Ishii, H., T. Yamauchi, Y. Asai, M. Okubo, H. Aoki, and S. Matsumoto, 2003: Multi-component monitoring of crustal activities in the deepest borehole $(1200 \mathrm{~m})$ in the world by a newly developed instrument. Abstracts of the Japan Earth and Planetary Science Joint Meeting 2003, S048-002.

Kawasaki, I., C. Oshima, N. Mikami, and S. Hori, 1991: A preliminary report on a search for silent and slow earthquakes around Japan islands. Zisin, J. Seismol. Soc. Japan, 44, 7583. (in Japanese)

Komaki, A., I. Kawasaki, K. Kokubo, M. Okubo, and T. Tsubokawa, 2006: A search for the Slichter mode excited by the 2004 great Sumatra-Andaman earthquake by use of the extensometer records in Japan. Abstracts of the Japan Geoscience Union Meeting 2006, S205-002.

Mikumo, T., and K. Aki, 1964: Determination of local phase velocity by intercomparison of seismograms from strain and pendulum instruments. J. Geophys. Res., 69, 721-731.

Miyabayashi, M., I. Kawasaki, Y. Imanishi, Y. Nishimae, S. Wakui, and O. Kamigaichi, 1999: Seismic Core-Modes observed by the $100 \mathrm{~m}$ quartz-tube extensometer at the Matsushiro Seismological Observatory of JMA. Abstracts of the Japan Earth and Planetary Science Joint Meeting 1999, De-020.

Okada, Y., K. Kasahara, S. Hori, K. Obara, S. Sekiguchi, H. Fujiwara, and A. Yamamoto, 2004: Recent progress of seismic observation networks in Japan - Hi-net, F-net, K-net and KiK-net . Earth Planets Space, 56, xv-xxviii.

Okamoto, T., Y. Ikegami, and K. Kokubo, 2007: Local effects on strain seismogram at matsushiro seismological observatory - 1. Love waves. Terr. Atmos. Ocean. Sci., 18, 547-565, doi: 10.3319/TAO.2007.18.3.547(T).

Takemoto, S., A. Araya, J. Akamatsu, W. Morii, H. Momose, M. Ohashi, I. Kawasaki, T. Higashi, Y. Fukuda, S. Miyoki, T. Uchiyama, D. Tatsumi, H. Hanada, I. Naito, S. Telada, N. Ichikawa, K. Onoue, and Y. Wada, 2004: A 100 m laser strainmeter system installed in a $1 \mathrm{~km}$ deep tunnel at Kamioka, Gifu, Japan. J. Geodyn., 38, 477-488. 
Taniguchi, K., and K. Oike, 1984: Behavior of fractured zones at the Yamasaki Fault for teleseismic surface waves. J. Phys. Earth, 32, 449-461.

Wessel, P., and W. H. F. Smith, 1995: A new version of the Generic Mapping Tools (GMT). EOS Trans. AGU, 76, 329.

Yamagishi, Y., S. Izumi, and K. Aihara, 1976: Observation of crustal deformation at Matsushiro. Q. J. Seismol., 41, 13-20. (in Japanese)

Okamoto, T., Y. Ikegami, and K. Kokubo, 2007: Local effects on strain seismograms at matsushiro seismological observatory - 2. Rayleigh waves. Terr. Atmos. Ocean. Sci., 18, 901-921, doi: 10.3319/TAO.2007.18.5.901(T). 